\title{
Brookhaven feels the heat over reactors
}

Long Island, New York. Despite a reputation among scientists and regulatory authorities as a good environmental 'citizen', Brookhaven National Laboratory has become the target of an increasingly strident campaign by local activists to curtail its activities - if not to shut it down altogether.

The laboratory, which hosts the National Synchrotron Light Source and is now constructing the Relativistic Heavy Ion Collider, is situated on Long Island, the increasingly crowded 100-mile stretch of land east of New York city. Radioactive emissions from its two research reactors, which operate at 3 and 30 megawatts of thermal power respectively, are small, even by stringent US environmental standards.

But activists, spurred by recent reports of environmental contaminants in the area, have been trying to link these closely-monitored emissions to a high rate of breast cancer. Television news reports have gone further, linking the laboratory to the plight of individual children with cancer.

The argument over the Brookhaven reactors has its roots in Long Island's lengthy history of anti-nuclear protest, which culminated in the dismantling and removal of a newly-built nuclear power plant at Shoreham a decade ago. At the time, opponents argued that Long Island's 2 million inhabitants could not be evacuated safely in the event of meltdown at the power station.

Now many of the same activists are turning their attention to the laboratory. They have been placing advertisements in local newspapers asking parents to send in baby teeth for radioactive analysis. In exchange, they are offering free copies of a publication called The Enemy Within: The High Cost of Living near Nuclear Reactors. The critics are also calling for a 'consumer boycott' of the universities that set up Associated Universities Inc. (AUI), which runs Brookhaven for the Department of Energy (DoE).

Their immediate objective is to shut down the 30-megawatt High Flux Beam Reactor (HFBR) - an important neutron source for US scientists - as well as the smaller medical research reactor. "We want them to close down the reactors," says Bill Smith, a local activist, predicting that this will happen "in the next 12 months". Smith runs a group called Fish Unlimited, which believes that traces of radionuclides from the laboratory are harmful to marine life.

The protests are taking their toll on the Brookhaven laboratory. Managers are increasingly preoccupied with public relations, while staff scientists are taunted by their neighbours. "The toughest thing is being accused of jeopardizing the lives of children," says Karl Swyler, a physicist at the laboratory who now works on education programmes inside Brookhaven and at local schools. The best thing the laboratory can do, he says, is "tell the truth and, when we screw up, admit it".

Brookhaven, which is used by scientists from a wide range of disciplines, has been trying to be more open about its activities, especially in the past two years. But the combination of this policy and hostility from its critics has served merely to draw more attention to the environmental problems.

For example, when the local Suffolk County health department found trichloroethane in groundwater near Brookhaven last year, DoE quickly agreed to pay for

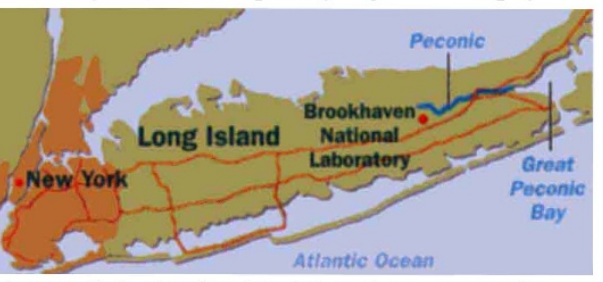
mpaigners link physics lab (above) to cancer in and want teeth for analysis (below right).

public water supplies for homes with wells in the affected area - even though Brookhaven scientists believe the contamination did not come from the laboratory. Some residents are now suing the laboratory for $\$ 1$ billion, claiming that the DoE's action implies guilt.

More recently, critics have been focusing on the laboratory's release of radioactive tritium from the HFBR into the Peconic river, which flows into Peconic Bay in Long Island's East End. They charge that the level of tritium in this river is 100 times that of any other in New York State, and have not been placated by the laboratory pointing out that the concentration is still only 10 per cent of the US drinking water standard.

In its effort to win back support, Brookhaven is sending its scientists frequently into local communities to explain their work. AUI has also provided facilities to support moderate community groups concerned about the lab.

In some cases this policy seems to be working. Jean Mannhaupt, a housewife and long-time critic of the lab, who asked for and got help from AUI to set up an 'advocates' office' at Brookhaven, says the laboratory's approach has been transformed for the better. She does not want the reactors closed, but is pressing for quicker action to remove spent fuel from temporary storage at the lab.

At a meeting two weeks ago at Southampton, a wealthy and environmentally sensitive community 20 miles east of the laboratory, senior Brookhaven managers sought to provide reassurance that the laboratory produces benefits for Long Island, and that past and present emissions are too small to threaten human health.

Bob Casey, head of safety and environ- mental protection at the laboratory, explained to the meeting, attended by about 100 people, the meaning of a curie of radiation, or a rem of exposure. To dramatize radiation risks, critics of the laboratory often talk about "picocuries"; Casey explained that there were 25 billion picocuries of tritium in a typical wristwatch.

According to Casey, the maximum additional exposure of someone living next to the laboratory will be 1 millirem, compared to a typical ambient exposure on Long Island of $200 \mathrm{mrem}$. Sue Davis, associate director of the laboratory, tried to quash a widespread perception that it performs nuclear weapons research. Only 2 per cent of its research work is defence-related, the laboratory says, and that is aimed at halting nuclear proliferation.

Public response to such assurances remains split. One activist, Roger Snyder, who has been picketing the laboratory gates every Saturday for a year, summed up the position of the critics. "What you are saying is 'trust the experts'. Well, we trusted you for 30 years," he told the Brookhaven officials. "I'd say your record is pretty poor."

Such attacks seem likely to continue. They are supported by a small but hardy group that includes Helen Caldicott, a physician and veteran anti-nuclear campaigner, and Jay Gould, a statistician and prominent critic of the lab, whose group, the Radiation

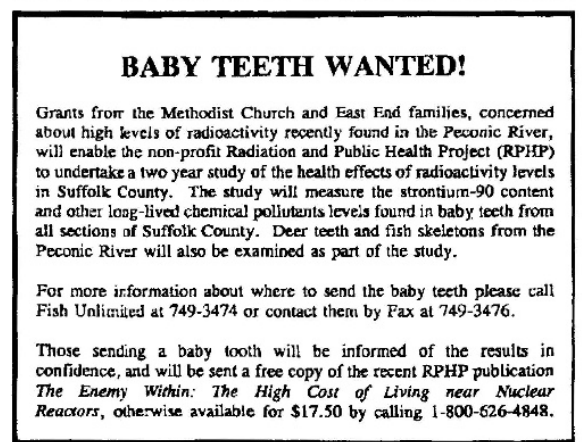

and Public Health Project, was responsible for the advertisement asking for baby teeth.

At the time of the dispute over the Shoreham power station, some scientists at Brookhaven expressed their personal support for the proposed reactor. Now there is clearly little love lost between this group and the activists who have focused their attack on the laboratory.

But so far the opponents have failed to mobilize widespread public support, and some feel that the laboratory has become paranoid about the activities of a relatively small group of citizens. Peter Boody, editor of the weekly Southampton Press, says that opposition to Brookhaven does not run very deep. But he says that the laboratory is "quite obsessed" by it. "They feel like a great whale with harpoons hanging out of its body."

Colin Macilwain 